Бахтин Евгений Леонидович

аспирант кафедры прикладной социологии

Уральского федерального университета

\section{ИНСТИТУТЫ ПОДДЕРЖКИ МОЛОДЕЖНОГО ПРЕДПРИНИМАТЕЛЬСТВА (НА ПРИМЕРЕ Г. ЕКАТЕРИНБУРГА)}

\section{Аннотация:}

Развитие малого и среднего предпринимательства, молодежной предпринимательской деятельности - одно из ключевых направлений экономического развития Российской Федерации на сегодняшний день. Данная статья посвящена изучению институциональных структур поддержки и развития молодежной предпринимательской деятельности на примере г. Екатеринбурга. Целью работы было описать институциональные структуры поддержки, которые способствуют развитию молодежного предпринимательства. В статье определены сильные и слабые стороны молодежного предпринимательства. В ходе изучения институциональных структур поддержки и развития предпринимательства социальные организации были разделены на три подгруппы. Был проведен вторичный анализ данных аналитических отчетов $и$ социологических опросов. В итоге исследования выявлено отсутствие адресной поддержки именно молодежного предпринимательства, а также проблема определения числа молодежи, занимающейся предпринимательской деятельностью.

Ключевые слова:

молодежь, предпринимательство, молодежное предпринимательство, предпринимательская деятельность, малое и среднее предпринимательство, инновации, институты поддержки предпринимательства, Екатеринбург.
Bakhtin Evgeny Leonidovich

PhD student, Applied Sociology Department, Ural Federal University

\section{INSTITUTES OF YOUTH BUSINESS SUPPORT \\ (THE CASE OF THE CITY OF YEKATERINBURG)}

Summary:

The development of small and medium-sized business and promoting youth business activity is one of the key areas of the economic development of the Russian Federation nowadays. The present research is devoted to the study of institutional structures providing for youth business support and development as in the case of the city of Yekaterinburg. The aim of the research is to describe institutional support structures facilitating the development of youth business activity. There are identified strengths and weaknesses of youth business. During the study of institutional structures of business support and development social organizations were divided into three subgroups. There was also conducted the secondary analysis of analytical reports and opinion polls results. The research revealed the lack of targeted support for youth business, as well as the problem of determining the exact number of young people engaged in business activity.

Keywords:

youth, business, youth business, business activity, small and medium-sized business, innovation, business support institutions, Yekaterinburg.

В условиях становления и активного развития рыночных отношений актуализируются вопросы поддержки молодежного предпринимательства как драйвера устойчивого развития современных общественных систем. Интерес к предпринимательству в системе общественных отношений и предпринимателям как социальной группе отражен в работах как западных (М. Вебер, К. Маркс, П. Сорокин, Э. Гидденс, П. Бурдье и др.), так и российских (Т. Заславская, В. Радаев, Г. Соколова, А. Чепуренко, О. Шкаратан и др.) исследователей. Так, согласно М. Веберу [1], предпринимательская деятельность - это воплощение рациональности: за честный и добросовестный труд человек получает честное вознаграждение, становясь (в русле протестантизма, для которого труд - добродетель) ближе к Богу.

Предприниматели как социальный слой весьма разнородны. Так, на заре становления рыночных отношений в России Т. Заславская выделила бизнес-слой, к которому отнесла всех людей, занятых бизнесом, включая и наемных работников [2].

Сегодня под предпринимательством принято понимать систему, включающую такие элементы, как свойства личности («предприимчивость»), разновидность хозяйственной практики (своя компания, или «бизнес»), а также собственно субъект социального действия («предприниматель») [3]. Предприимчивость - это деловая активность, инициативность, способность к начинанию и осуществлению дела, приносящего успех. Предпринять что-либо - значит сделать инициативное, упреждающее действие, проявить активность до того, как будут четко определены ее условия и последствия [4]. Предприниматель - это инициатор изменений, инноваций и новых способов производства [5, р. 2]. 
Современное предпринимательство молодеет. Молодежь является частью человеческого капитала, которую можно развивать, которая не имеет стереотипов и поэтому способна к динамичному ответу на вызовы общества. Для развития инновационной экономики требуется большое число специалистов, которые могут работать с новейшими технологиями в изменяющихся внешних условиях, и поэтому широкое вовлечение молодых людей в предпринимательскую деятельность является одним из эффективных путей решения данной проблемы. Талантливая молодежь способна генерировать идеи, она всегда являлась источником инноваций.

К конкурентным сторонам молодежного предпринимательства современные исследователи относят: высокую инновационность молодежного мышления, мобильность, гибкость и скорость принятия решений, быструю обучаемость и переобучаемость, способность выдерживать повышенные трудовые, нервные нагрузки, особенно на первоначальных этапах, рискованность [6]. Наряду с преимуществами следует обозначить и слабые стороны молодежного предпринимательства: недостаток опыта, отсутствие стартового капитала, недостаток социального капитала (социальных связей), отсутствие деловой репутации [7].

Для роста и укрепления молодежного предпринимательства важно создавать условия, при которых слабые стороны будут нивелироваться. Речь идет о необходимости формирования и воспроизводства норм, правил, стандартов, закрепленных в том числе и в нормативно-правовой базе, нацеленных на стимулирование предпринимательской активности молодого поколения. Для реализации уже существующих принципов и моделей вовлечения молодежи в предпринимательскую деятельность фрункционируют специально созданные институциональные структуры. В фрокусе нашего исследовательского внимания - институты поддержки молодежного предпринимательства, реализующие свою деятельность в крупном промышленном городе Екатеринбурге.

Существующие в городе институты поддержки предпринимательства мы разделили на три группы. Первую группу составляют структурные образования, работающие с микро-, малым и средним бизнесом. Деятельность второй группы институтов связана с поддержкой инновационных и технологических проектов и компаний. Третья группа институтов не является в полной мере структурой, нацеленной на поддержку предпринимательства молодежи, но включает в свою деятельность функции, способствующие эффективному и стремительному развитию предпринимательства. Отметим, что данное разделение достаточно условно и базируется на том, какими ресурсами обладает начинающий предприниматель на старте. При этом под ресурсами стоит понимать не только денежные активы молодых людей, но и накопленные знания, умения и навыки самого предпринимателя и его команды, социальный капитал, наличие собственных инновационных разработок, патентов и др.

Поддержкой микро-, малого и среднего предпринимательства молодежи в Екатеринбурге преимущественно занимаются Свердловский областной фонд поддержки предпринимательства, Екатеринбургский центр развития предпринимательства, Фонд поддержки молодежного предпринимательства «АГАТ». Свердловский областной фонд поддержки предпринимательства и Екатеринбургский центр развития предпринимательства осуществляют свою деятельность за счет государственного финансирования в рамках муниципальных [8] и региональных программ [9] поддержки и развития предпринимательства и воспроизводят основные принципы, заложенные в Федеральной программе «Экономическое развитие и инновационная экономика» [10].

Если начинающий, молодой предприниматель имеет инновационную идею, разработку, технологию, то он может обратиться в венчурные фонды. Большинство венчурных фондов имеют акселерационную программу. С инновационной идеей можно обратиться в следующие институциональные структуры: Свердловский венчурный фонд, Центр трансфера технологий УрФУ, Social Impact Award (для социального предпринимательства), Фонд содействия развитию малых форм предприятий в научно-технической сфере (Фонд содействия инновациям), а также принять участие в конкурсе школьных и студенческих предпринимательских проектов (Кубок «Преактум») и startup_reality.

К институциональным организациям, которые не занимаются поддержкой напрямую, но способствуют эффективному и стремительному развитию молодежного предпринимательства, можно отнести Уральскую торгово-промышленную палату (УТПП), объединения предпринимателей («ОПОРА России» (микро- и малый бизнес), Деловая Россия (средний бизнес), Свердловский областной союз промышленников и предпринимателей (крупный бизнес), Союз малого и среднего бизнеса Свердловской области). Кроме того, на территории крупного промышленного центра реализуется проект «Точка кипения», который нацелен на выявление предпринимательских идей и ресурсов молодого поколения. Молодые предприниматели также могут получить консультацию и поддержку со стороны Уполномоченного по защите прав предпринимателей в Свердловской области и депутатов Городской думы Екатеринбурга и Законодательного собрания Свердловской обла- 
сти (Комиссия по экономическому развитию и инвестициям, промышленности и предпринимательской деятельности Екатеринбургской городской думы, Комитет по промышленной, инновационной политике и предпринимательству). Эти институты наряду с широким спектром выполняемых функций включают в свою деятельность поддержку молодежного предпринимательства. Так, УТПП занимается внешнеэкономической деятельностью, развивает международные связи Свердловской области, соответственно, сотрудники Палаты готовы помочь выйти на зарубежные рынки с конкурентоспособным товаром или услугой. «Точка кипения» - это развивающее пространство, удобное для совместной работы над проектами будущего. Высокая плотность событий, вовлечение лидеров и талантливой молодежи дают возможность участникам быстро тестировать прорывные идеи, собирать проектные команды, находить единомышленников, учиться и учить, менять жизнь университета, города, региона, страны и мира к лучшему. Объединения предпринимателей представляют собой сообщества единомышленников, которые могут кооперироваться и сообща решать возникающие проблемы. Уполномоченный по защите прав предпринимателей в Свердловской области проводит дни приема предпринимателей совместно с Прокуратурой Свердловской области, помогая защитить и/или восстановить нарушенные права предпринимателей. Депутаты городской думы и Законодательного собрания принимают всех желающих и оказывают помощь в решении вопросов, связанных с предпринимательской деятельностью.

Для определения оценки удовлетворенности предпринимателей региона деятельностью институтов поддержки мы обратились к анализу материалов отчетов институциональных структур и социологических исследований. Согласно отчету о результатах социологического опроса по изучению общественного мнения предприятий и организаций о социально-экономической ситуации и деятельности Регионального объединения работодателей «Свердловский областной Союз промышленников и предпринимателей» [11], доля предпринимателей, отметивших неэффрективность мер поддержки бизнеса со стороны государства неизменно входит в топ негативных фракторов. Однако, рассматривая динамику, можно наблюдать положительный тренд: если в 2015 г. неудовлетворенность мерами высказало 46,4 \% представителей этой группы, то в 2018 г. - 30,7\%.

В исследовании среднего бизнеса, проведенном журналом «Деловой квартал» совместно с Райфффайзенбанком [12], утверждается, что только $15 \%$ респондентов состоят в отраслевых объединениях предпринимателей. Большинство предпринимателей средней руки не считают нужным вступать в бизнес-объединения и отраслевые союзы, а также обращаться за помощью в государственные фонды поддержки. Предприниматели, которые прибегали к их помощи, в большинстве случаев не считают это обращение полезным - 67,5 \% против 32,5 \% тех, кому в указанных учреждениях помогли.

Согласно данным Ежегодного доклада о результатах деятельности Уполномоченного по защите прав предпринимателей в Свердловской области [13], только каждый четвертый опрошенный считает деятельность этой структуры эффективной, а 81 \% предпринимателей никогда не пользовались государственной поддержкой.

Обращаясь к отчету о деятельности Свердловского областного фонда поддержки предпринимательства за 2018 год [14], можно обнаружить иную ситуацию, а именно высокую степень удовлетворенности предпринимателей работой этой структуры (4,1 балла по 5-балльной шкале оценки).

Представленные материалы позволяют сделать следующие выводы. Во-первых, оценка деятельности институтов поддержки предпринимательства в регионе выглядит противоречивой: социологические опросы фиксируют низкую степень удовлетворенности работой институтов, а отчетные материалы организаций, наоборот, демонстрируют их высокий потенциал и значимость. Вовторых, большая часть институциональных структур не концентрирует внимание на определенной возрастной группе, а старается охватить большое количество разных социальных групп, так как у каждой группы есть сильные и слабые стороны, т. е по сути можно говорить об отсутствии адресности в их деятельности. По этой причине сложно выделить организации, которые занимались бы исключительно поддержкой молодежного предпринимательства. В-третьих, в настоящее время сложно определить точное количество молодых предпринимателей в Екатеринбурге, так как службы статистики не разделяют предпринимателей по возрасту, а выделяют лишь субъекты микро-, малого и среднего, а также крупного предпринимательства. Мы полагаем, что для развития молодежного предпринимательства в крупном промышленном регионе необходимо включить его в особое направление молодежной политики и создать специализированные институты поддержки.

\section{Ссылки:}

1. Вебер М. Протестантская этика и дух капитализма // Вебер М. Избранные произведения: пер. с нем.; сост., общ. ред. и послесл. Ю.Н. Давыдова; предисл. П.П. Гайденко. М., 1990. С. 44-271. 
2. Заславская Т.И. Бизнес-слой российского общества: понятие, структура, идентификация // Мониторинг. 1994. № 5. C. 7-15.

3. Позняков В.П. Предприимчивость // Знание. Понимание. Умение. 2012. № 3. С. 345-346.

4. Там же.

5. Vesper K.H. New venture strategies. NJ, 1980. 303 p.

6. Карпунина М.А., Савинова С.Ю., Шубнякова Н.Г. Формирование молодежного предпринимательского сообщества как инструмент повышения предпринимательской активности в России [Электронный ресурс] // Современные проблемы науки и образования. 2014. № 2. URL: https://science-education.ru/ru/article/view?id=12360 (дата обращения: 12.12.2019).

7. Там же.

8. Об утверждении муниципальной программы «Развитие и поддержка малого и среднего предпринимательства в муниципальном образовании "город Екатеринбург” на 2017-2020 годы»: Постановление Администрации города Екатеринбурга Свердловской области от 26 октября 2016 г. № 2126 (ред. от 24.11.2017). Доступ из справ.-правовой системы «Гарант».

9. Об утверждении государственной программы Свердловской области «Повышение инвестиционной привлекательности Свердловской области до 2024 года»: Постановление Правительства Свердловской области от 17 ноября 2014 г. № 1002 (ред. от 29.12.2017). Доступ из справ.-правовой системы «Гарант».

10. Об утверждении государственной программы Российской Федерации «Экономическое развитие и инновационная экономика»: Постановление Правительства РФ от 15 апреля 2014 г. № 316 (ред. от 29.03.2019). Доступ из справ.правовой системы «Консультант Плюс».

11. Результаты социологического опроса по изучению общественного мнения предприятий и организаций о социальноэкономической ситуации и деятельности СОСПП за 2017 год [Электронный ресурс] // Аналитика «Свердловский областной Союз промышленников и предпринимателей». URL: http://sospp.ru/analitika/ (дата обращения: 16.05.19).

12. У бизнеса нет веры: уральские предприниматели привыкли к «болоту» стагнации. ИССЛЕДОВАНИЕ. Екатеринбург Деловой квартал [Электронный ресурc]. URL: https://ekb.dk.ru/news/u-biznesa-net-very-uralskie-predprinimateli-privyklik-bolotu-stagnatsii-237113846 (дата обращения: 16.05.19).

13. Ежегодный доклад о результатах деятельности [Электронный ресурс] // Официальный сайт Уполномоченного по защите прав предпринимателей в Свердловской области. URL: https://uzpp.midural.ru/article/show/id/134 (дата обращения: 16.05.19).

14. Отчеты [Электронный ресурс] // COФПП. URL: https://sofp.ru/about/documenty/otchetyi/ (дата обращения: 16.05.2019).

\section{References:}

'Annual Report on Operating Results', Official Website of Business Rights Commissioner of the Sverdlovsk Region, viewed 16 May, 2019, <https://uzpp.midural.ru/article/show/id/134>, (in Russian).

'Business Has No Faith: Ural Businessmen Got Used to the "Swampland" of Stagnation', RESEARCH. Yekaterinburg Delovoy Kvartal, viewed 16 May, 2019, <https://ekb.dk.ru/news/u-biznesa-net-very-uralskie-predprinimateli-privykli-k-bolotu-stagnatsii-237113846>, (in Russian).

'On Approval of a Municipal Program "Development and Support of Small and Medium-Sized Business in a Municipal Entity "The city of Yekaterinburg" for 2017-2020', Decree of the Administration of the City of Yekaterinburg of the Sverdlovsk Region as of 26 October 2016, no. 2126 (amended on 24 November 2017), Access from Garant computer-assisted legal research system, (in Russian).

'On Approval of the State Program of the Russian Federation "Economic Development and Innovation-Driven Economy", Decree of the Government of the Russian Federation dated 15 April 2014, no. 316 (amended on 29 March 2019), Access from Consultant Plus computer-assisted legal research system, (in Russian).

'On Approval of the State Program of the Sverdlovsk Region "Increasing Investment Prospects of the Sverdlovsk Region till 2024", Decree of the Government of the Sverdlovsk Region as of 17 November 2014, no. 1002 (amended on 29 December 2017), Access from Garant computer-assisted legal research system, (in Russian).

'Results of the Opinion Poll on the Issue of Studying Public Opinion of Enterprises and Institutions Regarding the SocioEconomic Situation and Activity of Sverdlovsk Regional Union of Industrialists and Entrepreneurs', Analitika "Sverdlovsk Regional Union of Industrialists and Entrepreneurs", viewed 16 May, 2019, <http://sospp.ru/analitika>, (in Russian).

Karpunina, MA, Savinova, SYu \& Shubnyakova, NG 2014, 'Building Youth Business Community as a Tool of Increasing Business Activity in Russia', Sovremennye Problemy Nauki i Obrazovaniya, no. 2, viewed 12 December 2019, <https://scienceeducation.ru/ru/article/view?id=12360>, (in Russian).

Poznyakov, VP 2012, 'Entrepreneurial Spirit', Znanie. Ponimamie. Umeniye, no. 3, pp. 345-346, (in Russian).

REPORTS, Sverdlovsk Regional Foundation for Business Support, viewed 16 May, 2019, <https://sofp.ru/about/documenty/otchetyi>, (in Russian).

Vesper, KH 1980, New Venture Strategies, NJ, 303 p.

Weber, M 1990, 'The Protestant Ethic and the Spirit of Capitalism', Selected Works, in YuN Davydov \& PP Gaidenko (eds), Moscow, pp. 44-271 (in Russian).

Zaslavskaya, TI 1994, 'Business Layer of the Russian Society: Concept, Structure, Identification', Monitoring, no. 5, pp. 7-15, (in Russian).

Редактор: Смирнова Светлана Леонидовна Переводчик: Герасимова Валентина Евгеньевна 